\title{
Letramento informacional, Covid-19 e infodemia
}

\author{
Information literacy, Covid-19 and infodemia
}

\author{
Alana Driziê Gonzatti dos Santosa,* (i) \\ Dayveson Noberto da Costa Pereirab (D) \\ Felipe Augusto Souza Moraisb \\ Maria Clara Lucena de Lemosb (i)
}

\begin{abstract}
RESUMO: As redes sociais acarretam o compartilhamento rápido de textos, independentemente de sua acuracidade. Na pandemia do novo coronavírus instalada no globo, esse cenário se tornou notório, com a disseminação massiva de notícias alarmantes, distorcidas ou criadas a partir de boatos acerca da temática. Diante disso, esta pesquisa objetivou caracterizar a infodemia da COVID-19 no Brasil, a partir do mapeamento de conteúdos quantitativos e qualitativos da internet e do conceito de letramento informacional. Os resultados contribuem para as discussões da área no que tange à busca e ao uso de informações e a avaliação de sua veracidade e relevância frente à COVID-19 no Brasil.
\end{abstract}

Palavras-chave: Letramento Informacional; COVID-19; Infodemia; Fake News.

ABSTRACT: Social networks cause quick sharing of texts, regardless of their accuracy. In the new coronavirus pandemic that reached the globe, this scenario became notorious, with the massive spread of alarming news, distorted or created from rumors about the theme. Given this, the research aimed to characterize the COVID-19 infodemia in Brazil, based on the mapping of quantitative and qualitative content on the internet and the concept of information literacy. The results contribute to the discussions in the area regarding the search and use of information and the assessment of its veracity and relevance in relation to COVID-19 in Brazil.

Keywords: Information Literacy; COVID-19; Infodemia; Fake News.

\footnotetext{
a Instituto Federal de Educação, Ciência e Tecnologia do Rio Grande do Norte, Macau, RN, Brasil.

b Programa de Pós-Graduação em Estudos da Linguagem, Universidade Federal do Rio Grande do Norte, Natal, RN, Brasil.

* Correspondência para/Correspondence to: Alana Driziê Gonzatti dos Santos. E-mail: alana.drizie@ifrn.edu.br. Endereço: Rua das Margaridas, 300, COHAB, Macau - RN, 59500-000.
}

Recebido em/Received: 28/04/2020; Aprovado em/Approved: 22/09/2020.

Artigo publicado em acesso aberto sob licença CC BY 4.0 Internacional $(1)$ 


\section{CONSIDERAÇÕES INICIAIS}

Em meio à era da informação, a prática de leitura na internet requer competências e habilidades específicas, voltadas para o reconhecimento, diante da grande quantidade de informações disponíveis, de dados relevantes e verídicos sobre determinado assunto. Além disso, diante das redes sociais (Facebook, Instagram, Whatsapp, Twitter), o compartilhamento de notícias ocorre de forma veloz, acarretando a disseminação rápida de textos, frequentemente sem o devido cuidado para a acuracidade do que está sendo enviado. Essa rede de atividade se concretizou, por exemplo, no primeiro semestre de 2020 , diante da pandemia do novo coronavírus, o que pode ser caracterizado como uma guerra da informação, em outras palavras, uma "infodemia".

Diante desse cenário, a pesquisa objetivou, de forma geral, caracterizar a infodemia da COVID-19 no Brasil e, especificamente, mapear fake news de grande circulação relacionadas à COVID-19 no contexto brasileiro; discutir o conteúdo desses dados a partir do conceito de letramento informacional, identificando temas, meios de circulação e configuração de textos; e apresentar estratégias para evitar a desinformação acerca da temática.

Considera-se que esta pesquisa é relevante, especialmente, em nível social, pois dialoga diretamente com um problema sincrônico e situado da sociedade, discutindoo e apresentando estratégias que possam impactar na sua diminuição. Para extrapolar os muros da instituição científica, o conhecimento construído a partir desta investigação foi publicizado por meio de materiais acessíveis aos usuários de redes sociais, como flyers, de modo que os resultados pudessem estar disponíveis para membros da sociedade em geral.

\section{LETRAMENTO INFORMACIONAL E INFODEMIA}

Este artigo é amparado teoricamente pelos estudos de letramento, especificamente, pelo letramento informacional (ACRL, 2000, 2015; GASQUE, TESCAROLO, 2010; MACHIN-MASTROMATTEO, 2015). Outro construto central para a investigação é o de infodemia e desinformação nas redes sociais, como as Fake News (BESSI et al, 2015; VICARIO et al, 2016, 2019; WARDLE, 2017; KIM et al, 2019; CINELLI et al, 2020; ZAROCOSTAS, 2020).

O letramento informacional (LI) é definido basilarmente como a capacidade de localizar informação, selecioná-la, acessá-la, utilizá-la e por meio dela gerar conhecimentos (GASQUE, TESCAROLO, 2010). Nesse sentido, trata-se da competência imbricada no processo de busca e uso eficiente, seguro e produtivo de dados, identificando sua relevância em determinado escopo.

Letramento informacional é o conjunto de habilidades integradas que abrange a descoberta reflexiva da informação, a compreensão de como informações são produzidas e valorizadas e o uso de informações na criação de novos conhecimentos e na participação 
ética em comunidades de aprendizagem. (ACRL, 2015, p. 8, tradução nossa $)^{1}$

Consoante a citação, é entendido como o modo de gestão dos dados a que temos acesso. Para isso, o indivíduo precisa ter o entendimento, de forma autônoma, de que deve adotar critérios para selecionar essa informação: autoridade, confiabilidade e atualidade são alguns deles.

No que tange ao primeiro critério, faz-se necessário que seja avaliada a credibilidade de determinado discurso baseando-se em quem é o seu produtor, especificamente, o conhecimento agregado que este possui a respeito da temática da qual trata, considerando-se sua experiência acadêmica, profissional e/ou social.

A respeito do segundo, a confiabilidade de uma informação se relaciona à verificação se determinado conteúdo apresenta-se de forma consistente, em seu sentido real, sem exageros, opiniões não fundamentadas ou distorções. Essa análise pode ser feita por meio da consulta a outras fontes ou informantes, por exemplo.

Ademais, a atualidade é um fator relevante para o sujeito, ou seja, a indicação de que determinado objeto informativo se refere a algo atual ou que ocorre no momento presente, tendo em vista que uma informação pode ter sido verdadeira ou amplamente aceita em determinado período, porém, após refutações ou novos fatos, passa a não refletir a realidade da época contemporânea.

Nessa linha, entende-se que

Um indivíduo letrado na esfera informacional é capaz de:

Determinar a extensão da informação necessária

Acessar a informação necessária de forma efetiva e eficientemente

Avaliar informação e sua fonte de forma crítica

Incorporar informações selecionadas a seu conhecimento prévio

Usar informação de forma eficiente para alcançar propósitos

específicos

Compreender problemas econômicos, legais e sociais em torno do uso da informação, e acessar e usar informação de forma ética e legal (ACRL, 2000, p. 2-3, tradução nossa) ${ }^{2}$

Essa busca da informação geralmente parte da necessidade do sujeito por algum conhecimento. Entretanto, de forma inversa, há situações em que o indivíduo é bombardeado por notícias, documentos, imagens etc, como em casos nos quais há interesse coletivo massivo em determinada temática. Nessas situações, pode ocorrer

\footnotetext{
${ }^{1}$ Texto original: Information literacy is the set of integrated abilities encompassing the reflective discovery of information, the understanding of how information is produced and valued, and the use of information in creating new knowledge and participating ethically in communities of learning. (ACRL, 2015, p. 8)

2 Texto original: An information literate individual is able to:

Determine the extent of information needed

Access the needed information effectively and efficiently

Evaluate information and its sources critically

Incorporate selected information into one's knowledge base

Use information effectively to accomplish a specific purpose

Understand the economic, legal, and social issues surrounding the use of information, and access and use information ethically and legally (ACRL, 2000, p. 2-3).
} 
a infodemia, termo cunhado primeiramente em 2003, no The Washington Post ${ }^{3}$, que reúne morfemas provenientes dos vocábulos informação e epidemia. É conceituado como o perigo da desinformação durante surtos de vírus (CINELLI et al, 2020), causado por rumores publicados sem informações oficiais que rapidamente acabam se espalhando devido ao compartilhamento dos usuários na rede.

Esse fenômeno tem tomado maiores proporções em uma sociedade imersa no ciberespaço, devido à extensão e variedade de conteúdos em redes sociais que podem ser criados e agregados pelo usuário. Nessa direção, a infodemia é um problema social que pode ter consequências drásticas: o compartilhamento contínuo de desinformação em meio a uma doença pandêmica pode gerar caos, surtos, pânico, desabastecimento, superlotação e a própria aceleração do processo epidêmico, que impactam diretamente em diversos setores, como na política, na economia e na saúde das pessoas. No contexto atual de mídias e tecnologias da comunicação, encontramonos no auge da problemática.

Inseridas nessa onda infodêmica de forma central estão as fake news, disfunções da informação causadas, por exemplo, pela construção de falsos contextos, conteúdo fabricado, enganoso ou manipulado. São categorizadas em Wardle e Derakhshan (2017) em relação a elementos (agente, mensagem e interlocutor), fases (criação, produção e disseminação) e tipos (misinformation, mal-information e disinformation).

Primeiramente, ao tratar do agente responsável por uma fake news, é necessário verificar se este se trata de perfil de informação oficial ou não, automatizado ou humano, bem como a motivação e o tipo de audiência pretendida. Acerca da mensagem, analisa-se se sua duração é vinculada a um evento específico ou possui curto/longo prazo; o grau de informatividade; a legalidade; e seu alvo. O que pode ser visualizado sobre o interlocutor nesse contexto é o tipo de ação que ele produz ao receber e consumir o conteúdo, a qual pode ser negativa, positiva ou nula.

Em segundo lugar, as fases de desenvolvimento de fake news incluem a criação da mensagem, sua posterior produção ou reprodução e distribuição, movimentos que podem ser feitos, inclusive, por diferentes agentes.

Em terceiro lugar, a respeito dos tipos, misinformation se refere a falsas informações, compartilhadas sem a intenção de causar danos; disinformation, por outro lado, possui em seu âmago essa intenção; já mal-information se trata de informações verdadeiras, porém confidenciais, que são publicizadas de modo a causar algum tipo de prejuízo.

Apesar de atual, o assunto é pouco discutido em trabalhos científicos em língua portuguesa, sendo esta investigação um modo de disponibilizar, em língua materna, informações relevantes acerca do termo e de seu impacto no contexto brasileiro.

\section{CONTEXTO DE INVESTIGAÇÃO}

Esta pesquisa possui relação com a abordagem exploratória, em primeiro momento, e, na sequência, com a explicativa. $O$ cunho de exploração foi utilizado no levantamento de dados a serem analisados, assim como pela leitura de exemplos que tratassem da questão em foco. O corpo desta discussão, porém, parte da pesquisa explicativa, por

3 Texto “When the Buzz Bites Back", por David Rothkopft, no The Washington Post. Disponível em: < https://www.washingtonpost.com/archive/opinions/2003/05/11/when-the-buzz-bites-back/bc8cd84f-cab6-4648-bf580277261af6cd/ > Acesso em 13 Mai 2020. 
meio da problematização das mensagens e dos fatores que ocasionam suas disfunções informacionais.

Constituiu-se a partir dos seguintes procedimentos metodológicos: busca de termos pesquisados no Google relacionando a COVID-19 a fake news no contexto brasileiro, por meio de termos presentes no Google Trends e de hashtags em alta nas redes; seleção de postagens em redes sociais que contenham fake news a respeito da COVID-19 no Brasil e que tenham sido compartilhados em grande escala; análise dos dados coletados a partir do letramento informacional; discussão de estratégias para evitar a desinformação acerca da temática.

A seleção das fake news se deu nas principais redes sociais utilizadas no Brasil (Whatsapp, Twitter, Youtube e Facebook), por meio da pesquisa por hashtags relacionadas ao coronavírus e diante da identificação de problemas informacionais em postagens de grande alcance nesses contextos ou que tenham sido divulgadas em massa. Para classificação dos problemas informacionais das mensagens analisadas (Quadros 1, 2 e 3), utilizaram-se os seguintes critérios, baseados em categorizações de fake news (WARDLE; DERAKHSHAN, 2017) e nos construtos teóricos do letramento informacional (ACRL, 2000, 2015; GASQUE, TESCAROLO, 2010; MACHINMASTROMATTEO, 2015): credibilidade do agente, agente automatizado, informação desatualizada, falso contexto, linguagem utilizada, conteúdo fabricado, enganoso, ilegal ou manipulado, motivação econômica ou política e intenção de dano.

Com base nos objetivos traçados, mescla os paradigmas qualitativo e quantitativo, caracterizando-se como mista, a partir da reunião de dados numéricos (estatísticas e gráficos) e subjetivos (discursos propagados em redes sociais) para sua construção, gerados no período de fevereiro, mês em que ocorreu a primeira confirmação de caso do novo coronavírus no Brasil (25/02/2020), a abril de 2020, quando já havia aproximadamente noventa mil casos confirmados da doença no território nacional.

Diante desse espaço temporal, três temáticas foram selecionadas para análise, com o critério de terem tido grande variedade de notícias falsas em circulação no Brasil, a saber: informações sobre o vírus, medicamentos contra o coronavírus e quarentena como medida de enfrentamento à pandemia. A partir dos exemplares, discutimos, em nossa análise, seu conteúdo, por meio dos temas, meios e números de circulação e sua configuração. Na sequência, apresentamos uma discussão de estratégias contra a desinformação, com base nos dados analisados.

\section{INFORMAÇÕES SOBRE O VÍRUS}

Diversas semioses são utilizadas para disseminar fake news sobre o vírus SARS-CoV-2, a fim de tornar a (des)informação mais acessível aos potenciais interlocutores. Exemplo disso é o vídeo que afirma, em tom conspiratório, que a China foi responsável pela fabricação do novo coronavírus, arquitetando, assim, uma possível guerra biológica que resultaria no enfraquecimento da economia norte-americana. 
Figura 1 - Vídeo publicado no YouTube e compartilhado nas redes sociais

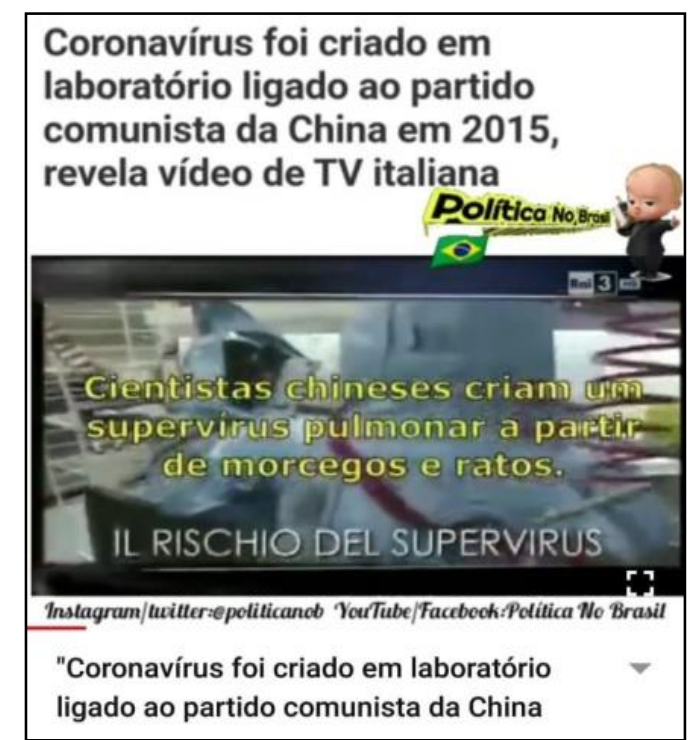

Disponível em: https://youtu.be/kdtQEAJ6O8I Acesso em 14 Abr 2020.

Embora o vídeo exista de fato, trata-se de uma reportagem italiana cuja intenção foi divulgar uma experiência desenvolvida por pesquisadores norte-americanos e chineses e publicada, em 2015, pela revista científica "Nature", acerca de uma hibridização de coronavírus de morcego. Não há qualquer evidência que demonstre relação entre a pandemia atual e esse experimento. Diante da grande repercussão dessa fake news, haja vista ela ter circulado em várias partes do mundo, tanto a revista quando a TV italiana (Radiotelevisione - RAl) que divulgou a pesquisa já se pronunciaram a seu respeito, esclarecendo o conteúdo vinculado.

Para dar maior credibilidade à informação e, assim, garantir que o vídeo seja compartilhado amplamente pelo interlocutor, a notícia é reproduzida na íntegra, porém descontextualizada. É válido observar ainda a legenda sobreposta, a qual relaciona a criação do vídeo apenas à China, explicitando sua gestão por um Partido Comunista, e elide a participação norte-americana, embora o próprio vídeo apresente os Estados Unidos como financiadores da pesquisa. Além disso, entra na constituição do vídeo o logotipo do grupo autointitulado "Política no Brasil", com contas em diversas redes sociais.

Em oposição a esse discurso, existe aquele que evidencia os jogos políticos que amparam a construção do vídeo, sobretudo quando se tem em conta o crescimento econômico da China nas últimas décadas, em razão dos superávits comerciais, da diminuição das importações e do aumento das exportações, e a sua ameaça aos Estados Unidos, considerada a maior potência econômica do globo. Nessa direção, dizer que o vírus se originou na China seria favorável aos Estados Unidos, tendo em vista que as relações comerciais da China com outros países ficariam prejudicadas.

Contudo, parece confuso, no primeiro instante, o porquê de o vídeo circular intensamente no Brasil, uma vez que este país mantém relações comerciais com a China. No contexto brasileiro, a circulação do vídeo justifica-se devido à proximidade político-ideológica entre os presidentes Jair Messias Bolsonaro e Donald Trump, ambos nacionalistas de direita e neoliberais. Isso fica mais claro quando algumas escolhas lexicais são ativadas para diferenciar o Brasil e os Estados Unidos da China, como o termo "comunista" presente na legenda do dado em análise. 
Certamente, ao compartilhar um vídeo como esse, nem todos estarão atentos aos jogos de interesse subjacentes a ele. O compartilhamento, em alguns casos, se deve apenas ao fato de o material ter sido produzido por uma empresa estatal de televisão e rádio, na Itália. Com isso, os três critérios necessários para selecionar a informação autoridade, confiabilidade e atualidade - são automaticamente acionados, mas não conferidos por quem a dissemina. Uma rápida pesquisa nos principais sites de busca seria suficiente para verificar a desatualização da informação e a constatação da fake news ${ }^{4}$.

Outra fake news disseminada em larga escala nas redes sociais que reforça o discurso de ódio contra a China diz respeito à exportação de seus produtos. Nela, afirma-se que o consumo de bens originados no país é arriscado em razão de ele ter sido o primeiro a detectar casos de pessoas infectadas pela COVID-19. É verdade que o vírus sobrevive algumas horas em superfícies, podendo haver variação no tempo a partir do material no qual ele está fixado, conforme pesquisa publicada na revista científica New England Journal of Medicine ${ }^{5}$. Acontece que, até chegar no Brasil, onde a fake news tem grande circulação, as mercadorias passam muitos dias em transporte, tempo suficiente para tornar o vírus inativo.

De forma similar, também se divulgou amplamente nas redes sociais que o plástico bolha utilizado para embalagem de produtos chineses possui ar contaminado, reforçando a ideia de que seria arriscado importar mercadorias do país. Na rede social Twitter, onde a hashtag \#BoicoteAChina foi criada, várias publicações (tweets) abordaram essa questão.

\section{Figura 2 - Tweets sobre plástico bolha}
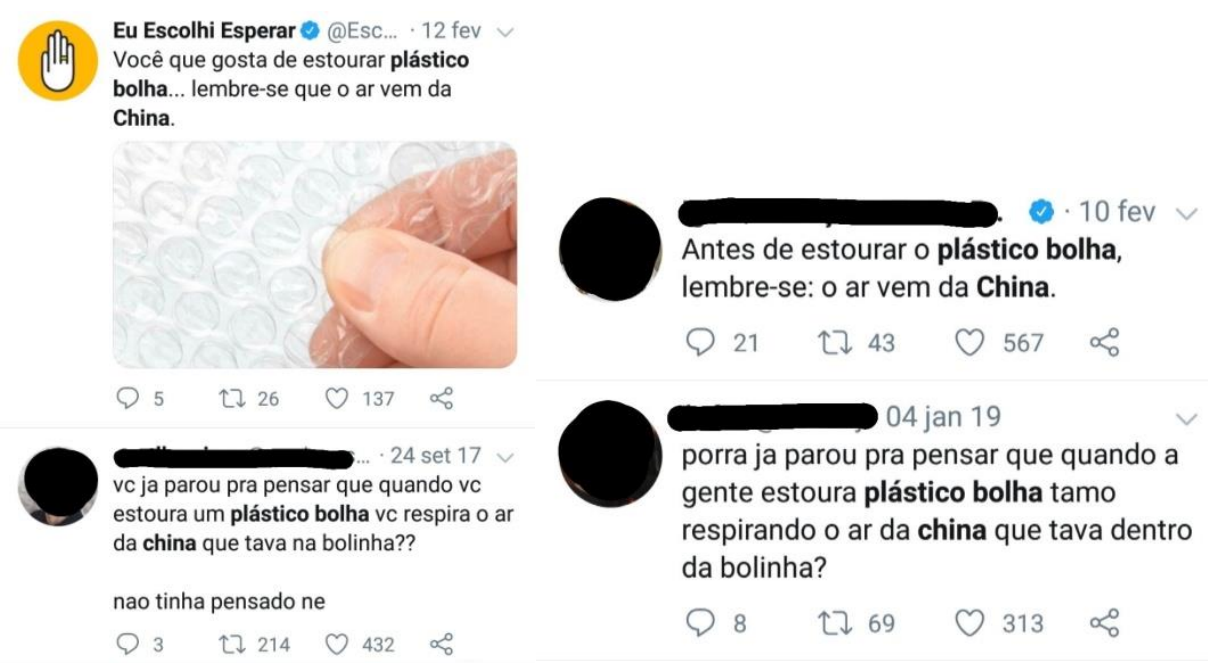

Disponível em: https://twitter.com/escolhiesperar Acesso em 18 Abr 2020.

\footnotetext{
${ }^{4}$ Notícia publicada no Jornal Estadão, em 19/03/2020: Coronavírus: estudo desmente teoria conspiratória sobre a criação em laboratório da China https://politica.estadao.com.br/blogs/estadao-verifica/coronavirus-estudo-desmenteteoria-conspiratoria-sobre-criacao-em-laboratorio-da-china/

5 Trata-se do trabalho "Aerosol and Surface Stability of SARS-CoV-2 as Compared with SARS-CoV-1". Disponível em: https://www.nejm.org/doi/full/10.1056/NEJMc2004973 Acesso em 20 Abr 2020.
} 
$\mathrm{Na}$ aba de pesquisa da rede social, foram utilizadas as palavras-chave "plástico bolha" e "China", a fim de verificar o nível de propagação da mensagem. Observa-se que seu conteúdo é antigo, aparecendo em tweets de 2017. Inclusive, os tweets publicados nos dias 24 de setembro de 2017 e 04 de janeiro de 2019, quando casos de COVID-19 já haviam sido registrados na província de Hubei, possuem estrutura frasal idêntica, com questionamentos e escolhas lexicais semelhantes. Os dois outros tweets, publicados em fevereiro de 2020, em perfis com grande número de seguidores, também apresentam estrutura frasal padronizada e, de modo similar aos anteriores, são concisos e não utilizam links direcionados para vídeos ou textos mais complexos, facilitando, desta forma, a internalização da mensagem por seus leitores.

Esta fake news, especificamente, gerou uma postagem no site do Ministério da Saúde ${ }^{6}$ com o propósito de desmenti-la. Para tanto, afirmou-se que o vírus sobrevive por poucas horas fora do corpo humano e que o tempo de chegada das mercadorias é longo, argumentos que vão de encontro, cabe dizer, à pesquisa aqui mencionada.

Diferentemente da fake news anterior, em que o material consegue passar credibilidade aos interlocutores em razão de seu contexto de produção, a informação sobre o plástico bolha, por outro lado, é mais passível de questionamentos imediatos. Isso ocorre porque os critérios para seleção e compartilhamento de informações, explicados em seção anterior, apresentam lacunas perceptíveis, sobretudo no que diz respeito à credibilidade e à confiabilidade: a credibilidade é baixa por não haver, no grupo de pessoas que tweetaram o enunciado, emissores capacitados para validar a informação; por sua vez, a confiabilidade é baixa por não haver explicações consistentes para a informação vinculada aos tweets, os quais a pulverizam como constatação.

O fato de o SARS-CoV-2 ter baixa estabilidade nas superfícies não faz dele um vírus pouco danoso ao ser humano, quando comparado a outros vírus. Nesse sentido, mostra-se válida para esta discussão a análise da fake news a seguir.

\footnotetext{
${ }^{6}$ A postagem, publicada em 12/02/2020, pode ser visualizada a partir do link:

<https://www.saude.gov.br/fakenews/46366-plastico-bolha-e-o-novo-coronavirus-e-fake-news> Acesso em 10 Mar 2020.
} 


\section{Figura 3-Tweet sobre H1N1 e Coronavírus}

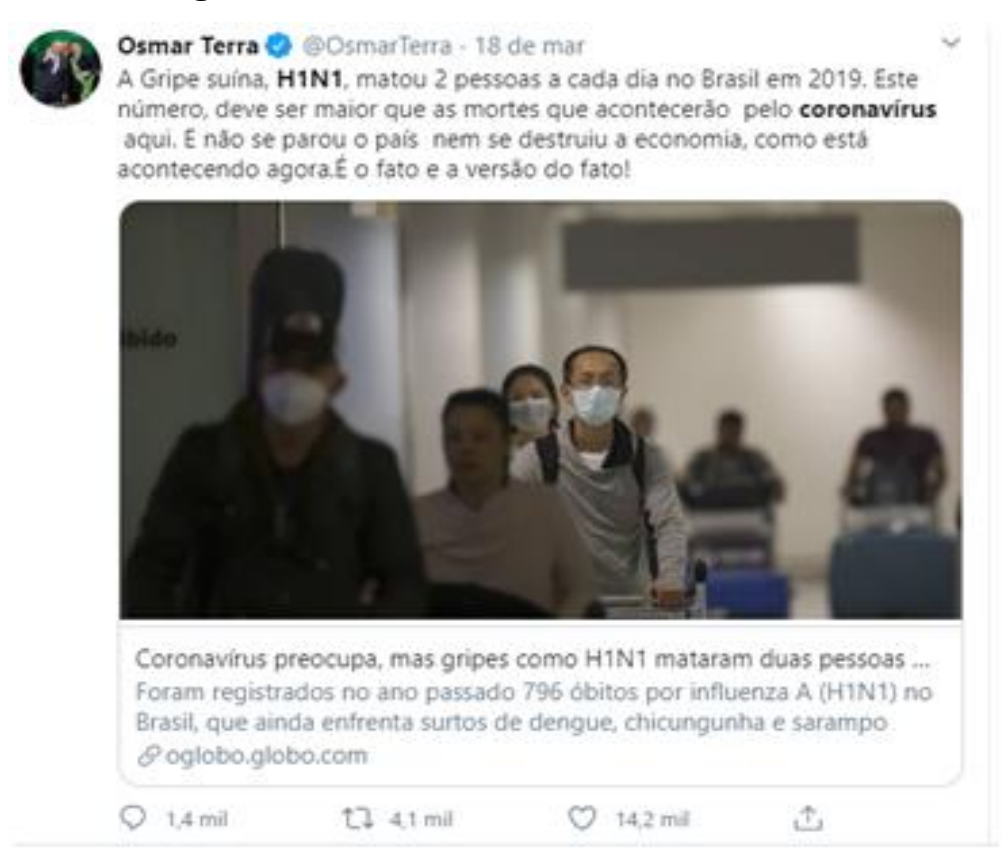

Disponível em: https://shorturl.at/erstz Acesso em 18 Abr 2020.

O tweet acima é de autoria de Osmar Terra, médico e político brasileiro, cotado para ser ministro da saúde no governo de Jair Bolsonaro, e traz uma previsão do número de mortes por COVID-19 no Brasil. Para tal, uma comparação foi feita com o H1N1, subtipo do vírus influenza conhecido popularmente como "gripe suína", com o propósito de atenuar os possíveis efeitos da nova pandemia. Entretanto, deve-se considerar que os vírus SARS-CoV-2 e H1N1 possuem algumas diferenças, a começar pela velocidade de propagação, conforme mostrou a Organização Mundial de Saúde (OMS)․

Além disso, a postagem ocorreu em um momento inicial da doença no país, quando existiam 428 infectados confirmados em todo território, segundo o Ministério da Saúde, e pouco se sabia a respeito do vírus. Contudo, enquanto menos de 500 contaminações tinham sido registradas no Brasil até a data de publicação do tweet, a OMS havia contabilizado, no mesmo dia, 200 mil casos da doença e 8 mil mortes em todo o mundo, mostrando que os casos de contaminação por COVID-19 avançavam em outras nações e que, portanto, também poderiam avançar no país.

Essas informações, certamente, não foram consideradas pelas 14 mil pessoas que curtiram o tweet. Ocorre que Osmar Terra, além de ter sido cotado ao cargo de ministro da saúde, é médico e, por essa razão, passa credibilidade no que diz.

Deve-se observar também que, para subsidiar o seu dizer, o médico acrescentou, de forma estratégica, uma notícia sobre a comparação das pandemias publicada no jornal O Globo ${ }^{8}$, em 31 de janeiro de 2020, ou seja, 18 dias antes de sua publicação, quando os casos confirmados de novo coronavírus eram menores no Brasil. Se verificarmos a

\footnotetext{
7 Trata-se do relatório “Coronavirus disease 2019 (COVID-19) Situation Report - 46", disponível em <https://apps.who.int/iris/handle/10665/331443> Acesso em 30 Abr 2020.

${ }^{8}$ Notícia publicada no site do jornal O Globo, 31/01/2020: Coronavírus preocupa, mas gripes como H1N1 mataram duas pessoas por dia no país. Disponível em: <https://oglobo.globo.com/sociedade/coronavirus-preocupa-mas-gripescomo-h1n1-mataram-duas-pessoas-por-dia-no-pais-em-2019-24222429> Acesso em 30 Abr 2020.
} 
quantidade de casos no Brasil no período de fevereiro a abril de 2020, porém, vemos que ultrapassou 3 mil óbitos, contrariando a previsão do médico e político.

Em seu texto, Osmar Terra mostra-se preocupado com a economia do país (colocandoa, inclusive, acima das mortes causadas por COVID-19), sobretudo após alguns estados terem decretado a quarentena. Para concluir o texto, ele escreve "É o fato e a versão do fato!", mostrando, com suas próprias palavras, que defender o isolamento social seria uma "versão do fato" (logo, refutável) e que seu posicionamento, o qual minimiza os efeitos da pandemia, seria o "fato" (logo, irrefutável). Em outros termos, mas seguindo a lógica do médico e político Osmar Terra: "contra fatos não há argumentos".

De forma semelhante à primeira fake news analisada, na qual um jornalista italiano explica a criação de um vírus por cientistas chineses, neste tweet também temos um emissor que, sendo médico, passa credibilidade no seu dizer. Embora o critério "autoridade" nos ajude a compreender melhor o porquê dessa informação ter repercutido em larga escala, não podemos desconsiderar que a confiabilidade e a atualidade também entram como critérios acionados previamente pelos potenciais interlocutores antes da interação com o tweet (comentário, retweet e curtida), haja vista ser ele validado por uma explicação que aparenta consistência, em um momento marcado pela nova pandemia. Por essa razão, quando comparada às duas informações falsas analisadas, esta se mostra mais fiel à realidade, inclusive porque, diferentemente da primeira, houve, desta vez, a apropriação de uma notícia recente, divulgada por uma empresa jornalística de abrangência nacional.

Diante das discussões, ressaltam-se, de forma resumida, os seguintes problemas em informações sobre o vírus aqui analisadas:

Quadro 1 - Análise da infodemia do COVID-19 em foco

\begin{tabular}{|l|l|}
\hline Texto & Problema informacional \\
\hline Figura 1 - Vídeo publicado no Youtube & $\begin{array}{l}\text { - Informação desatualizada } \\
\text { - Falso contexto } \\
\text { - Conteúdo manipulado } \\
\text { - Motivação política }\end{array}$ \\
\hline Figura 2 - Tweets sobre plástico bolha & $\begin{array}{l}\text { - Conteúdo enganoso } \\
\text { - Credibilidade do agente }\end{array}$ \\
\hline Figura 3 - Tweet sobre H1N1 e Coronavírus & $\begin{array}{l}\text { - Conteúdo manipulado } \\
\text { - Falso contexto } \\
\end{array}$ \\
& $\begin{array}{l}\text { - Informação desatualizada } \\
\text { - Motivação econômica }\end{array}$ \\
\hline
\end{tabular}

\section{MEDICAMENTOS CONTRA O NOVO CORONAVÍRUS}

A partir de mapeamento realizado no Google Trends no contexto brasileiro dentro do período temporal em análise, a pesquisa do termo "coronavírus" sugeriu que, logo abaixo de temáticas de prevenção e sintomas do vírus, em quarta posição, estava a junção de termos "cloroquina coronavírus", a qual sofreu aumento repentino de procura a partir do dia 18 de março. Além disso, em décima sétima posição nas pesquisas, constava o assunto "ivermectina coronavírus", outra junção entre a doença e um medicamento. 


\section{Figura 4 - Pesquisa pelo termo “cloroquina” no período e contexto em análise}

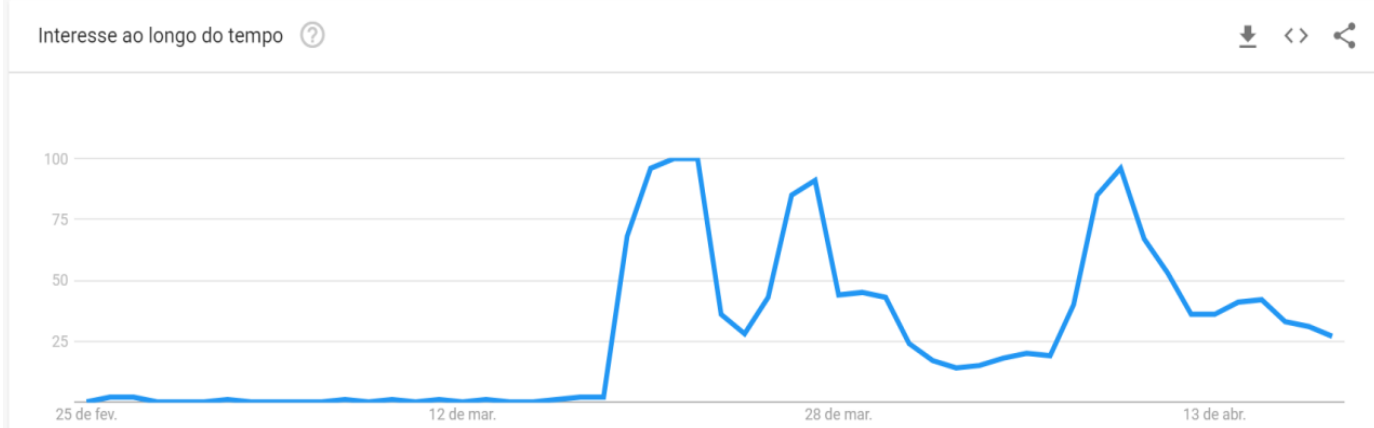

Disponível em: https://shorturl.at/duJPR Acesso em 26 Abr 2020.

Esses resultados reverberam a ocorrência de buscas específicas por remédios contra o coronavírus, especialmente que estão alvo de pesquisas científicas para comprovação de sua eficácia no tratamento. Uma figura notória que pode ter sido crucial para os picos nas buscas por cloroquina foi o presidente do país, Jair Bolsonaro, que, por meio de tweets (março/abril), lives nas redes sociais (26 e 30/03/2020), entrevistas e pronunciamentos oficiais na televisão (08/04/2020), defendeu o uso da medicação, alegando que esta não possuía efeitos colaterais e solicitando seu uso desde o início de tratamentos de saúde no enfrentamento do vírus ${ }^{9}$, dentro no período em análise. Um registro escrito desse posicionamento, realizado em 27/03/2020, está presente em sua conta verificada no Twitter:

Figura 5 - Postagem publicada no Twitter, que obteve mais de trinta mil curtidas

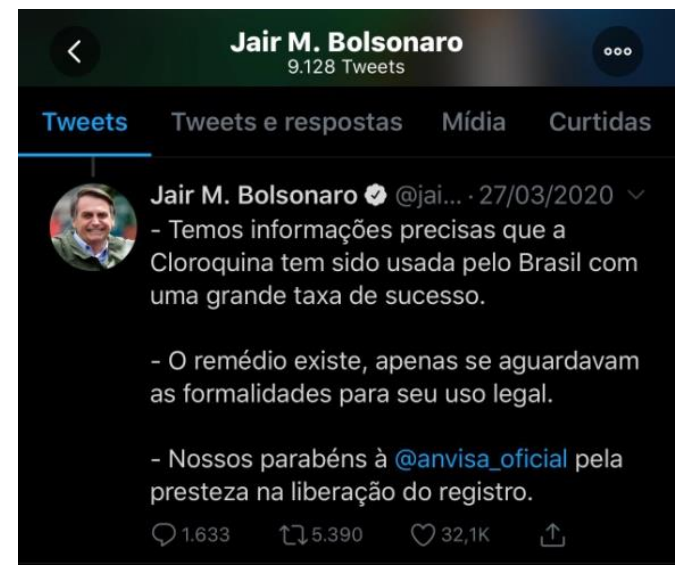

Disponível em: https://twitter.com/jairbolsonaro Acesso em 17 Abr 2020.

Ao indicar "informações precisas" da eficácia da droga, com "uma grande taxa de sucesso", o político dá garantia a toda uma população que acompanha suas orientações como líder nacional acerca do uso da cloroquina. Isso gerou também uma

9 Notícia publicada no site da Revista Veja, 17/04/2020: Cloroquina: a ascensão e queda do remédio que iria nos salvar da crise. Disponível em: <https://veja.abril.com.br/politica/cloroquina-a-ascensao-e-queda-do-remedio-que-iria-nossalvar-da-crise/> Acesso em 20 Abr 2020. 
pressão sobre os hospitais, para que iniciassem o uso da medicação em seus pacientes. Diante desse cenário, outra fake news surgiu na mesma rede social: no dia 07/04/2020, "Curado por cloroquina" foi um termo chave nas buscas do Twitter; diversos usuários narraram a cura de parente por cloroquina, utilizando o mesmo texto-base, conforme imagem a seguir:

Figura 6 - Postagens publicadas nas redes sociais
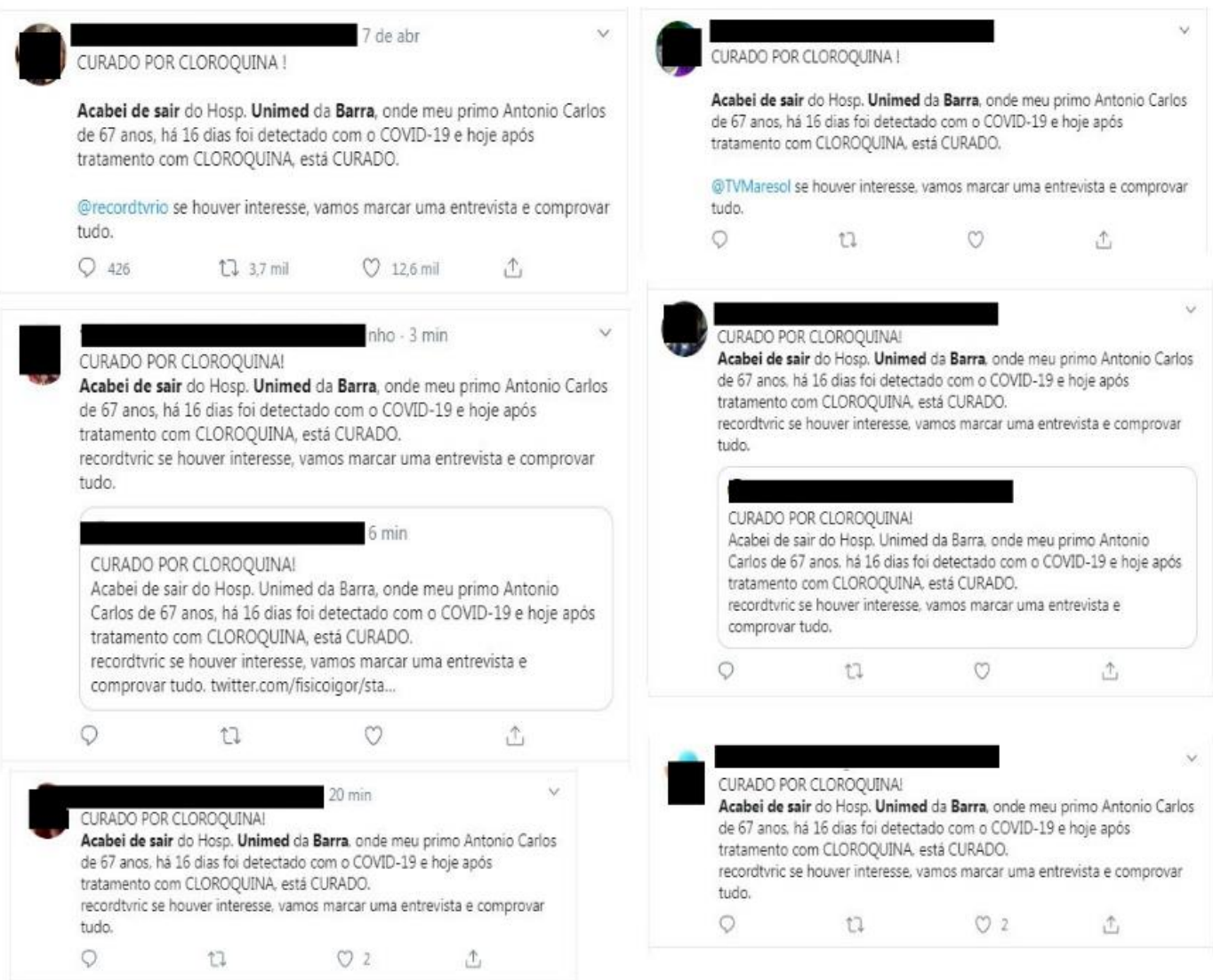

Disponível em: https://www.instagram.com/p/B-ww7nSHHEu/ Acesso em 10 Abr 2020.

A primeira postagem, presente na lateral superior esquerda da Figura 6, foi a original, publicada em perfil que, ao final do período de investigação, continha mais de 40 mil seguidores. Ela rapidamente foi replicada em diversas outras contas da rede social, conforme exemplares apresentados na imagem anterior.

Esse mecanismo de disseminação de informações é denominado de bot, fenômeno em que um sistema simula ações de forma repetitiva na web, o que, nesse caso, pode ter sido utilizado para criar perfis falsos ou utilizar perfis já existentes na rede social e publicar as mensagens, no objetivo de aumentar visualizações sobre o assunto em formato de spam. Esse fato já seria o suficiente para discriminar tentativa de desinformação acerca da temática, mas, além disso, o próprio hospital citado no tweet chegou a se pronunciar, negando ter tratado o paciente nomeado ${ }^{10}$.

\footnotetext{
${ }^{10} \mathrm{O}$ Estadão desmentiu a série de tweets por meio de verificação direta com o hospital citado. Disponível em: $<$ https://politica.estadao.com.br/blogs/estadao-verifica/hospital-nega-que-tenha-tratado-primo-antonio-carlos-comcloroquina/> Acesso em $20 \mathrm{Abr} 2020$.
} 
Apesar dessa movimentação acerca da cloroquina desde o mês de março, que causou aumento exponencial na venda do medicamento e consequentemente desabastecimento da droga em farmácias ${ }^{11}$, apenas no dia 13 de abril de 2020 foi publicada, em fase preliminar, a primeira pesquisa brasileira ${ }^{12}$ sobre o tratamento com cloroquina em território nacional. Inclusive, a investigação teve de ser interrompida por questões de segurança, após demonstrar a morte de sujeitos que receberam uma dosagem alta da medicação.

Após essa divulgação, o presidente do país e outros apoiadores do uso imediato e universal do remédio passaram a ter mais cautela no discurso relacionado ao medicamento em questão. Entretanto, não demorou para que conspirações acerca dos resultados apresentados na investigação surgissem. É o caso da postagem no Facebook de Talita Oliveira (conta verificada), deputada estadual pelo PSL na Bahia, em perfil seguido por quase 100 mil pessoas, em 16/04/2020:

\section{Figura 7 - Postagem publicada na página do Facebook da deputada (1)}

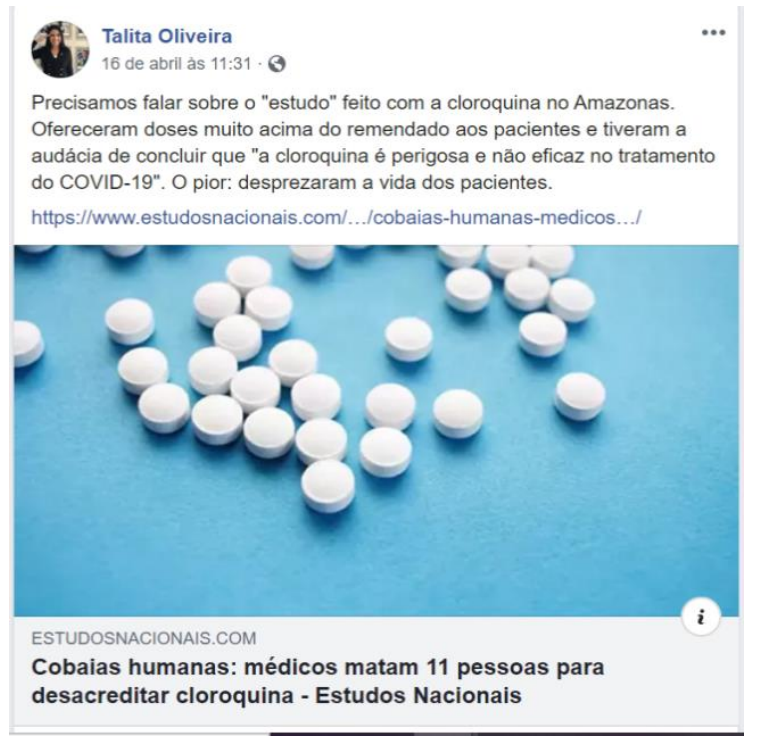

Disponível em: https://www.facebook.com/deputadatalitaoliveira/ Acesso em 25 Abr 2020.

Ao desqualificar o estudo científico, por meio do uso das aspas em seu discurso, a deputada instiga seu público à leitura de blog jornalístico que insinua que os médicos responsáveis pela investigação criticada teriam assassinado pacientes com o intuito de desacreditar o medicamento ${ }^{13}$. O conteúdo é grave, pois acusa os pesquisadores envolvidos de praticar crime, sem apresentar evidência comprobatória. Além disso, trata-se de informação falsa, pois a pesquisa obteve autorização da Comissão Nacional

\footnotetext{
${ }^{11}$ Notícia veiculada no portal O Globo, em 21/03/2020: Coronavírus: desaparecimento da cloroquina das farmácias do Rio preocupa pacientes usuários de medicamentos. Disponível em: <https://oglobo.globo.com/sociedade/coronavirusservico/coronavirus-desaparecimento-da-cloroquina-das-farmacias-do-rio-preocupa-pacientes-usuarios-demedicamentos-24318959> Acesso em 20 Abr 2020.

${ }_{12}$ Trata-se do trabalho "Difosfato de cloroquina em duas dosagens diferentes como terapia adjuvante de hospitalizados com síndrome respiratória grave no contexto de infecção por coronavírus (SARS-CoV-2): Resultados preliminares de segurança de um ensaio clínico de fase Ilb randomizado, duplo-cego (estudo CloroCovid-19)". Disponível em: <https://www.medrxiv.org/content/10.1101/2020.04.07.20056424V1.full.pdf>Acesso em 20 Abr 2020.

13 Texto “Cobaias humanas: médicos matam 11 pessoas para desacreditar cloroquina”, de 15/04/2020. Disponível em: <https://www.estudosnacionais.com/23127/cobaias-humanas-medicos-matam-11-pessoas-para-desacreditarcloroquina/> Acesso em 17 Abr 2020.
} 
de Ética em Pesquisa e seguiu todas as recomendações legais para sua realização, conforme nota lançada pela Fundação Oswaldo $\mathrm{Cruz}^{14}$.

No dia 15/04/2020, a mesma deputada publicou o texto abaixo em sua página do Facebook. A postagem foi compartilhada na plataforma, durante o período desta pesquisa, mais de 54 mil vezes, além de ter sido replicada por diversos veículos de notícias.

Figura 8 - Postagem publicada na página do Facebook da deputada (2)

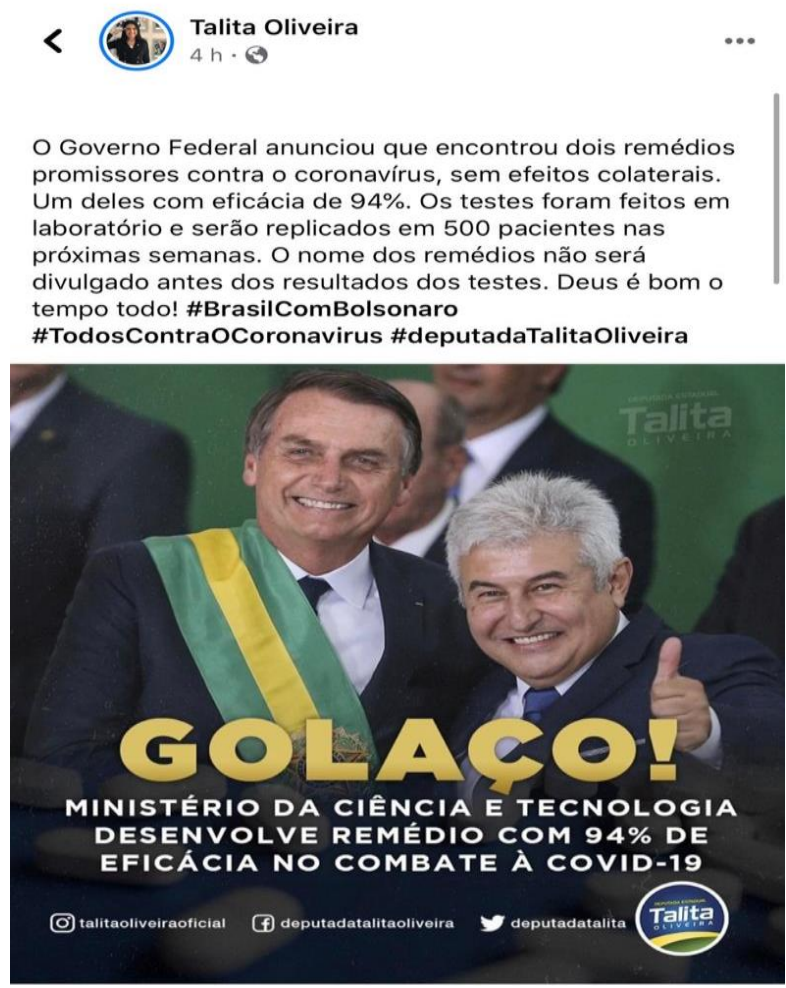

Disponível em: https://www.facebook.com/deputadatalitaoliveira/ Acesso em 25 Abr 2020.

A postagem apresenta diversos problemas informacionais. O primeiro deles é não mencionar o nome do medicamento, o que gerou uma onda de suposições na internet. Com a inclusão da nitazoxanida na listagem de remédios controlados pela Agência Nacional de Vigilância Sanitária, no mesmo dia do anúncio, chegou-se ao nome do remédio Anitta, normalmente usado em verminoses.

Outro problema é a construção "Ministério da Ciência e da Tecnologia desenvolve remédio", que leva à compreensão de que o medicamento se trata de novo fármaco, o que não é o caso, pois o próprio ministro afirmou ser um medicamento já à venda e de fácil acesso, além do entendimento de que a descoberta estivesse vinculada estritamente ao governo/ministério em questão, quando trata-se de investigação realizada por cientistas em universidades e institutos de pesquisa.

\footnotetext{
14 Fiocruz divulga nota em defesa da ciência e de seus pesquisadores, em 17/04/2020. Disponível em: <https://portal.fiocruz.br/noticia/fiocruz-divulga-nota-em-defesa-da-ciencia-e-de-seus-pesquisadores > Acesso em 20 Abr 2020.
} 
Por fim, apresentar uma taxa de eficácia alta leva à criação de falsa expectativa na sociedade em geral de que o remédio já esteja aprovado em todas as suas fases de testes, com sua eficácia comprovada e pronto para distribuição. Entretanto, essa taxa é referente a análises in vitro, sem maiores dados conclusivos. Com isso exposto, entende-se que a publicação foi tendenciosa e exagerada em relação a seu conteúdo.

No período de dois dias, o assunto chegou a atingir números altos de pesquisas no Google Trends, mas o interesse diminuiu gradativamente, conforme observado a seguir:

\section{Figura 9 - Pesquisa pelo termo “Anitta remédio coronavírus" no período mar-abr 2020}

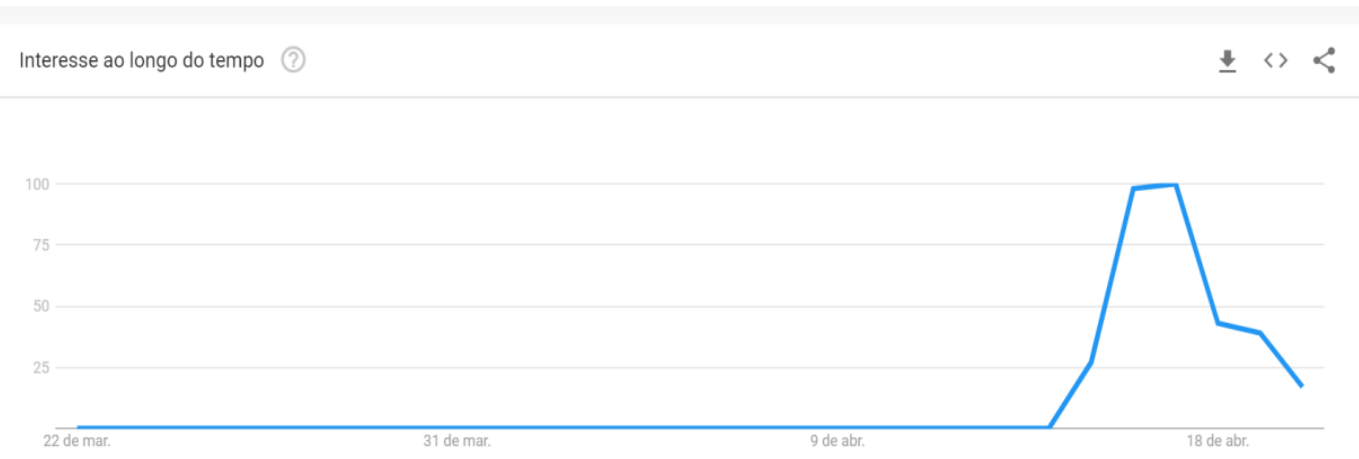

Disponível em: https://shorturl.at/ceFL8 Acesso em 26 Abr 2020.

O desinteresse veio de novas informações, veiculadas em jornais com grande circulação do país" e apresentava diversos problemas e pouca eficácia no tratamento da COVID-19, o que reverbera a desinformação causada pela postagem inicial acerca do assunto.

Nessa direção, as informações sobre medicamentos contra o novo coronavírus veiculadas nesta análise apresentam os seguintes problemas:

Quadro 2 - Análise da infodemia do COVID-19 em foco

\begin{tabular}{|l|l|}
\hline Texto & Problema informacional \\
\hline $\begin{array}{l}\text { Figura 5 - Postagem publicada no Twitter, que } \\
\text { obteve mais de trinta mil curtidas }\end{array}$ & $\begin{array}{l}\text { - Conteúdo manipulado } \\
\text { - Motivação política }\end{array}$ \\
\hline $\begin{array}{l}\text { Figura } 6 \text { - Postagens publicadas nas redes } \\
\text { sociais }\end{array}$ & - Agente automatizado \\
\hline $\begin{array}{l}\text { Figura } 7 \text { - Postagem publicada na página do } \\
\text { Facebook da deputada (1) }\end{array}$ & - Conteúdo fabricado \\
\hline
\end{tabular}

\footnotetext{
${ }^{15}$ Folha de São Paulo: Remédio secreto de Pontes é pior que cloroquina para Covid-19, diz estudo chinês. Disponível em: <https://www1.folha.uol.com.br/colunas/monicabergamo/2020/04/remedio-secreto-de-pontes-e-pior-quecloroquina-para-covid-19-diz-estudo-chines.shtml> Acesso em 20 Abr 2020.

Correio Braziliense: Chineses já testaram medicamento "secreto" do ministro Pontes, em 17/04/2020. Disponível em: <https://www.correiobraziliense.com.br/app/noticia/brasil/2020/04/17/interna-brasil,845744/chineses-ja-testarammedicamento-secreto-do-ministro-pontes.shtml> Acesso em 20 Abr 2020.
} 


\begin{tabular}{|c|c|}
\hline & - Conteúdo enganoso \\
\hline $\begin{array}{l}\text { Figura } 8 \text { - Postagem publicada na página do } \\
\text { Facebook da deputada ( } 2 \text { ) }\end{array}$ & $\begin{array}{ll}\text { - } & \text { Motivação política } \\
\text { - } & \text { Conteúdo manipulado } \\
\text { - } & \text { Falso contexto }\end{array}$ \\
\hline
\end{tabular}

Vale ressaltar, porém, que nenhum componente fármaco até o momento tem sua eficácia contra a doença confirmada e amplamente referendada por entidades especializadas da saúde, em nível mundial e/ou local, apesar de diversos testes clínicos estarem em desenvolvimento.

\section{QUARENTENA COMO MEDIDA DE ENFRENTAMENTO}

Considerando investigações realizadas de cenários previstos do coronavírus no Brasil (WALKER, WHITTAKER, WATSON, 2020), o impacto de medidas de isolamento social precoce poderia chegar a menos um milhão de mortes no contexto brasileiro.

Essa previsão auxiliou diversos dirigentes brasileiros quando do início dos decretos de isolamento social, ocorridos, em sua maioria, na primeira quinzena de março de 2020 , pouco tempo após a confirmação do primeiro caso de COVID-19 no Brasil. O isolamento precoce parece ter "se inspirado" em países que não o adotaram e que sofreram com o crescente número infectados, a exemplo de Itália e Estados Unidos. Nesse sentido, as proposições brasileiras a respeito da suspensão de aulas, expedientes em centros comerciais, jornada reduzida em fábricas de itens "não essenciais", entre outros, configuraram o movimento popularmente conhecido por quarentena.

Essas medidas impactaram a sociedade de diversas formas. No contexto educacional, por exemplo, professores precisaram aprender, em dias, a ministrar aulas online enquanto crianças e jovens de todas as faixa-etárias precisaram, confinados, assistir aulas virtuais e realizar ainda mais atividades que o comum, pais precisaram lidar com processos educativos dos quais se eximiam. No campo econômico, também houve inúmeros impactos. Restaurantes, bares e casas de shows tiveram de fechar as portas por tempo indeterminado. Empresas de pequeno porte precisaram reduzir suas folhas de pagamento e empresas da área do turismo viram sua demanda despencar. Fábricas pararam a produção e setores considerados não essenciais perderam arrecadação.

É visível que o confinamento, precoce ou não, afetou diretamente a economia brasileira (e estende-se à mundial). Desse modo, o Estado precisou, em caráter de urgência, propor pacotes econômicos que evitassem a falência de alguns negócios e/ou que evitassem que parte da população fosse levada de volta aos cenários de fome, endividamento e caos econômico. Ainda assim, as medidas, pensadas a curto prazo, não dão conta da totalidade do problema e geram opiniões controversas. Nesse sentido, cidadãos não conformados com o isolamento social como garantia de prevenção e enfrentamento à pandemia, se mostram incomodados com as medidas, usando, para manifestar tal insatisfação, as redes sociais. É por meio delas que os indivíduos se manifestam contrários às medidas e propõem soluções não comprovadas cientificamente, como se vê na Figura 10. 
Figura 10 - Publicação do Facebook em apologia ao fim do isolamento social

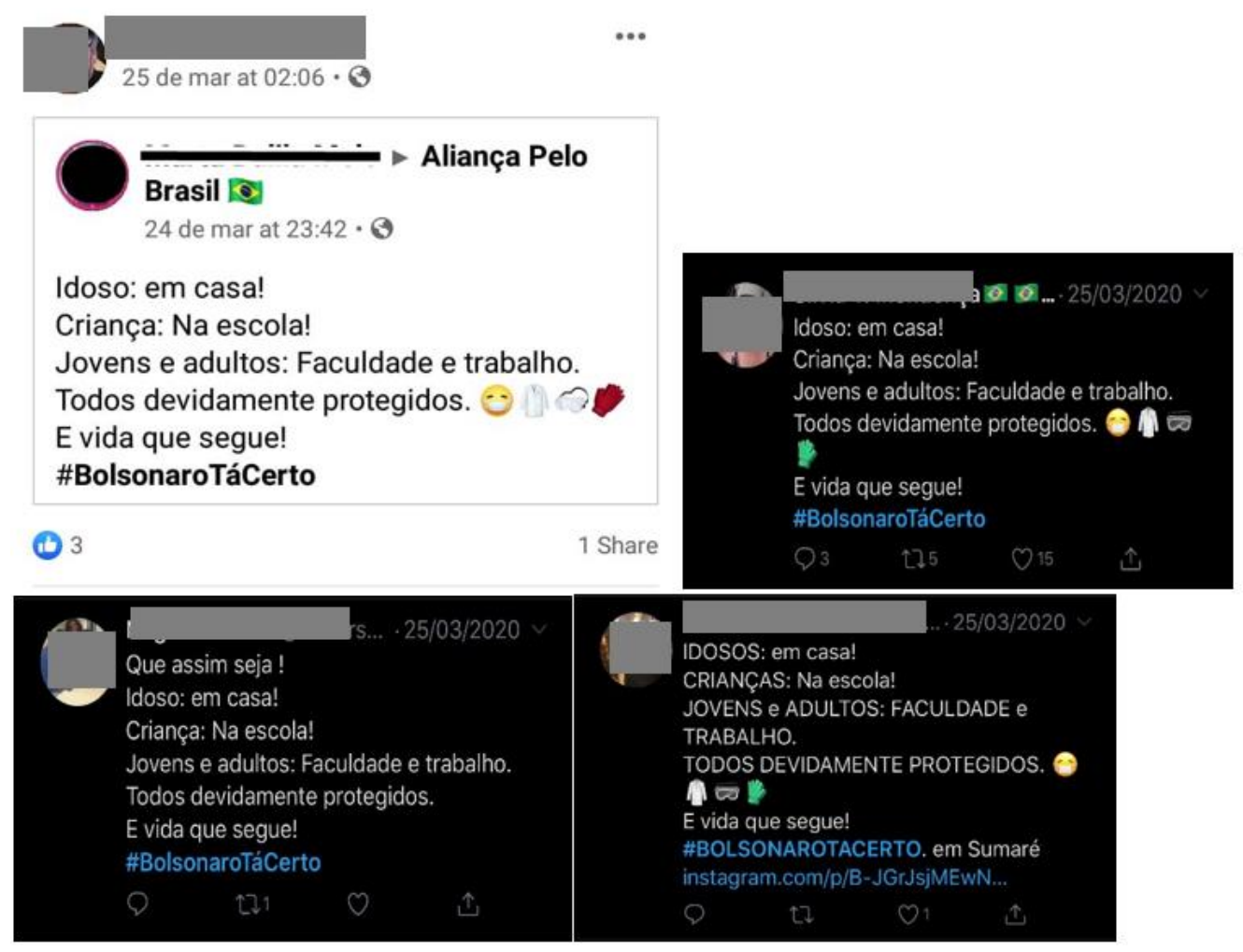

Disponível em: https://www.facebook.com/eliocesar.marson e https://twitter.com/hashtag/bolsonarotacerto. Acesso em 25 março 2020.

Na Figura 10, tem-se uma publicação veiculada nas redes sociais Facebook e Twitter que consiste numa "repostagem" de um conteúdo publicado em um grupo fechado do Facebook denominado "Aliança pelo Brasil". Vê-se, pela disseminação do material em várias redes, que muitos indivíduos se sentiram impelidos a compartilhar o conteúdo em suas contas pessoais. Na postagem, o que se defende é que apenas os idosos, considerados grupo de risco, devem realmente ficar em casa, ao passo que os demais indivíduos da cadeia econômica devem voltar às atividades normais, fazendo a economia girar. Essa ideologia se pauta na falsa compreensão de que i) apenas idosos devem estar em isolamento completo pois figuram grupo de risco; ii) crianças são assintomáticas e não correm riscos; iii) jovens e adultos, responsáveis pelo giro da máquina econômica, precisam seguir a vida normalmente.

Essas premissas são consideradas falsas e constituem fake news justamente porque i) o grupo de risco não é apenas composto por idosos, mas estudos e estatísticas indicam que todos podem adquirir a doença e, portanto, são vulneráveis a ela; ii) crianças não só podem contrair o vírus, como ir a óbito em virtude dele (conforme estatísticas), e, além disso, por serem majoritariamente assintomáticas, são vetores de contaminação; e iii) ao assumir que todos devem voltar ao normal apenas se "devidamente protegidos", há uma assunção do risco de contaminação e do consequente crescimento da curva epidemiológica.

Por fim, na mesma postagem, em forma de hashtag e recebendo destaque, a informação de que "Bolsonaro está certo". Essa afirmação indica, de forma subentendida, que o presidente do país é contrário às medidas de isolamento tomadas até então (orientadas por estudos e pela Organização Mundial da Saúde). Outro fator 
contextual que fez com que tal postagem ganhasse visibilidade tem a ver com quem a publica. O responsável pela repostagem explorada na Figura 10 é um médico, cirurgião plástico, que veio à óbito em virtude da COVID-19 ${ }^{16}$. Esse cenário indica que não só a população "comum" está à mercê de informações falsas, mas cidadãos da ala médica estão na linha de frente não só do combate, mas também da divulgação de fakes news.

Inspirado na mesma lógica dessa postagem, a Figura 11 retrata uma convocação para uma carreata na cidade de Mossoró/RN ${ }^{17} \mathrm{com}$ vistas a defender o fim do isolamento social. Na publicação, utiliza-se o termo "em defesa do emprego".

Figura 11 - Convocação para carreata em defesa do emprego

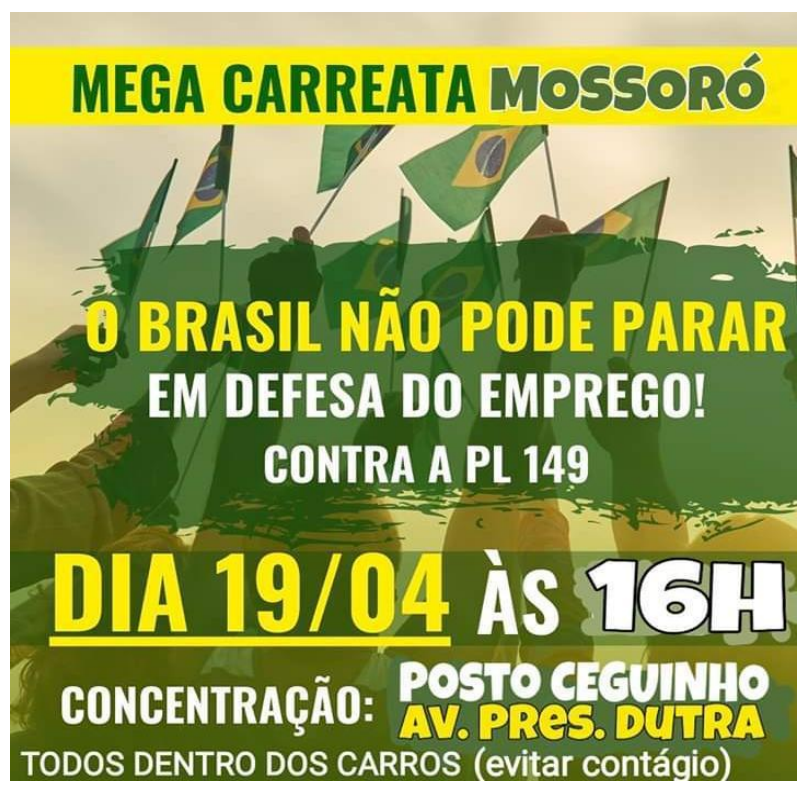

Disponível em: https://shorturl.at/fQU56 Acesso em 25 Abr 2020.

Considerando o cenário da pandemia da COVID-19 e dadas as medidas de isolamento social, os impactos sobre a economia de fato acontecem. Uma vez que empresas estão fechadas, há uma onda de desemprego que tem atingido parte da população. Entretanto, essa não deveria ser a maior preocupação das pessoas posto que o cuidado com a vida deve vir em primeiro lugar. Na Figura 11, é justamente esse cuidado que parece não haver.

Cidadãos conclamam os demais a participarem uma carreata em defesa do emprego, isto é, contra o fim do isolamento social e a favor da retomada das atividades, alegando que o Brasil não pode parar. É interessante perceber a contradição constante no banner. Embora o ato defenda a retomada de atividades comuns, ele admite a probabilidade de alto contágio pela doença quando não há isolamento ou distanciamento social. Para perceber isso, basta observar o rodapé da publicação, onde se diz, em letras garrafais, "todos dentro dos carros (evitar contágio)". Nesse

\footnotetext{
${ }^{16}$ Disponível em: <https://g1.globo.com/rn/rio-grande-do-norte/noticia/2020/04/16/medico-de-52-anos-morre-comcoronavirus-em-mossoro-rn.ghtml> Acesso em 30 Abr 2020.

${ }^{17} \mathrm{Em} 16$ de abril de 2020, Mossoró, cidade situada no oeste do Rio Grande do Norte, contabilizava 84 casos positivos para o COVID-19 e 6 óbitos decorrentes dele, ocupando o $2^{\circ}$ lugar na lista de municípios com mais casos confirmados. Os dados foram divulgados pela Secretaria Estadual de Saúde (SESAP/RN). Disponível em <https://agorarn.com.br/cidades/secretaria-de-saude-de-mossoro-confirma-7a-morte-por-coronavirus-rn-tem-21obitos/> Acesso em 30 Abr 2020.
} 
sentido, constitui-se uma publicação baseada em informações falsas quando a) afirmase que o Brasil não pode parar, mas o que está temporariamente suspenso são apenas serviços não essenciais, e não todas as atividades; e b) quando admite-se que é necessário manter o distanciamento social para evitar contágio, mas reivindica a normalidade de atividades não essenciais.

Essas noções não surgem do nada. Pelo contrário, elas são fortemente fomentadas por governantes - que deveriam estar na linha de frente contra qualquer possibilidade de contágio. É o que se vê na Figura 12, que se trata de publicações em contas verificadas do presidente da República e de um de seus ministros de Estado, o da educação, respectivamente.

\section{Figura 12 - Publicações de governantes nas redes sociais}
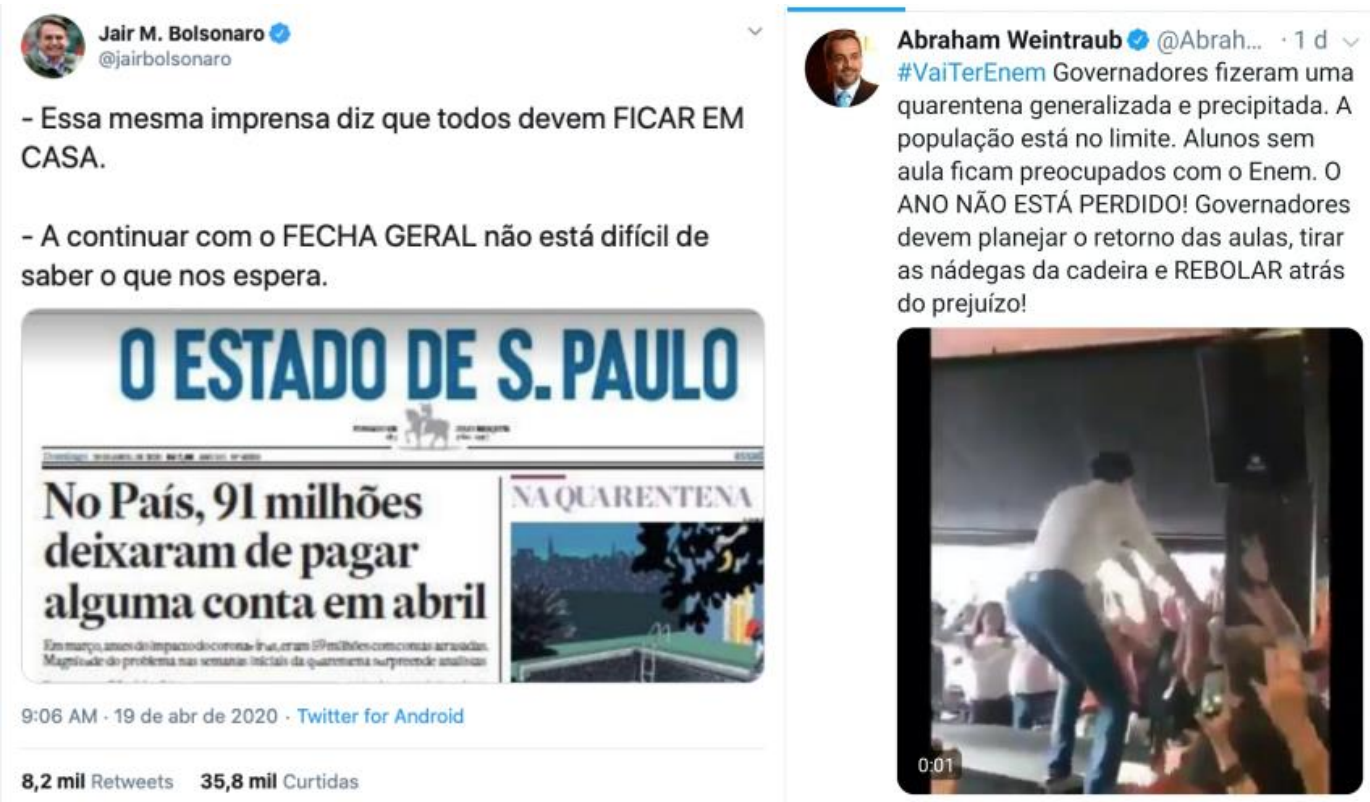

Disponível em: https://shorturl.at/xDKV3. Acesso em 20 Abr 2020.

Disponível em: https://shorturl.at/drxE6. Acesso em 20 Abr 2020.

Na Figura 12, constam duas publicações retiradas do perfil pessoal no Twitter do presidente Jair Bolsonaro, em 19 de abril de 2020, e do ministro da educação Abraham Weintraub, também no dia 19 de abril de 2020, respectivamente. Na primeira, Bolsonaro reforça, a partir de uma manchete de jornal, que o isolamento social traz prejuízos à economia e, de forma subentendida, indica descontentamento com tais medidas, sugerindo que elas não sejam mais atendidas. À direita, Weintraub é incisivo quanto ao adiamento ou não do Exame Nacional do Ensino Médio - ENEM. Segundo ele, haverá ENEM na data prevista porque as medidas de quarentena precoce tomadas pelos governadores foram precipitadas. Na mesma imagem, o ministro utiliza expressões de baixo calão ("tirar as nádegas da cadeira e rebolar") e aparece dançando junto a apoiadores, sem respeitar as medidas de distanciamento.

Partindo das discussões empreendidas, os seguintes problemas foram observados, de forma geral: 
Quadro 3 - Análise da infodemia do COVID-19 em foco

\begin{tabular}{|c|c|}
\hline Texto & Problema informacional \\
\hline $\begin{array}{l}\text { Figura } 10 \text { - Publicação do Facebook em apologia } \\
\text { ao fim do isolamento social }\end{array}$ & $\begin{array}{l}\text { - Credibilidade do agente } \\
\text { - Conteúdo enganoso } \\
\text { - Motivação política }\end{array}$ \\
\hline $\begin{array}{l}\text { Figura } 11 \text { - Convocação para carreata em defesa } \\
\text { do emprego }\end{array}$ & $\begin{array}{l}\text { - Conteúdo enganoso } \\
\text { - Motivação econômica }\end{array}$ \\
\hline $\begin{array}{l}\text { Figura } 12 \text { - Publicações de governantes nas } \\
\text { redes sociais (esquerda) }\end{array}$ & $\begin{array}{l}\text { - Intenção de dano } \\
\text { - Motivação política }\end{array}$ \\
\hline $\begin{array}{l}\text { Figura } 12 \text { - Publicações de governantes nas } \\
\text { redes sociais (direita) }\end{array}$ & $\begin{array}{l}\text { - Conteúdo enganoso } \\
\text { - Conteúdo manipulado } \\
\text { - Intenção de dano } \\
\text { - Linguagem utilizada } \\
\text { - Motivação política }\end{array}$ \\
\hline
\end{tabular}

$\mathrm{Na}$ contramão de todas essas informações falsas, autoridades brasileiras de governo de estados orientaram as medidas de isolamento desde o mês de março de 2020, suavizando significativamente a curva de contaminação e, consequentemente, diminuindo o número de vítimas fatais. O estudo de Walker, Whittaker e Watson (2020) indicou que as medidas de distanciamento social tomadas por 11 países europeus evitaram, até a data de conclusão do estudo, 120 mil mortes. Esse estudo fez com que diversas autoridades mudassem de ideia quanto às medidas de isolamento. Líderes como Donald Trump (Estados Unidos), Giuseppe Conte (Itália), Andrés Manuel López Obrador (México) e até Vladimir Putin (Rússia) passaram a defender que a população ficasse em casa. Em oposição, Jair Bolsonaro (Brasil) e Daniel Ortega (Nicarágua) seguem entre os poucos líderes que não apoiam o distanciamento social.

\section{ESTRATÉGIAS CONTRA A DESINFORMAÇÃO}

Mesmo diante de dados científicos, parte da população, como se viu nas seções anteriores, se volta a acreditar em inverdades - diversas vezes espalhadas pelos líderes de estado - e/ou em fake news que circulam nas redes sociais. Sendo assim, que estratégias assumir para evitar a desinformação ou diminuir as consequências dela, ou seja, ampliar o letramento informacional do usuário?

Na Figura 13, é possível identificar notas informativas produzidas por uma séria Instituição de Ensino. Essas notas visam à aproximação da sociedade de informações científicas de forma simplificada. É preciso, então, que os cidadãos se comprometam a sempre verificar a procedência das informações em que acreditam e/ou que replicam, buscando refletir e pesquisar acerca do agente/produtor da informação. 
Figura 13 - Notas informativas publicadas e replicadas nas redes sociais

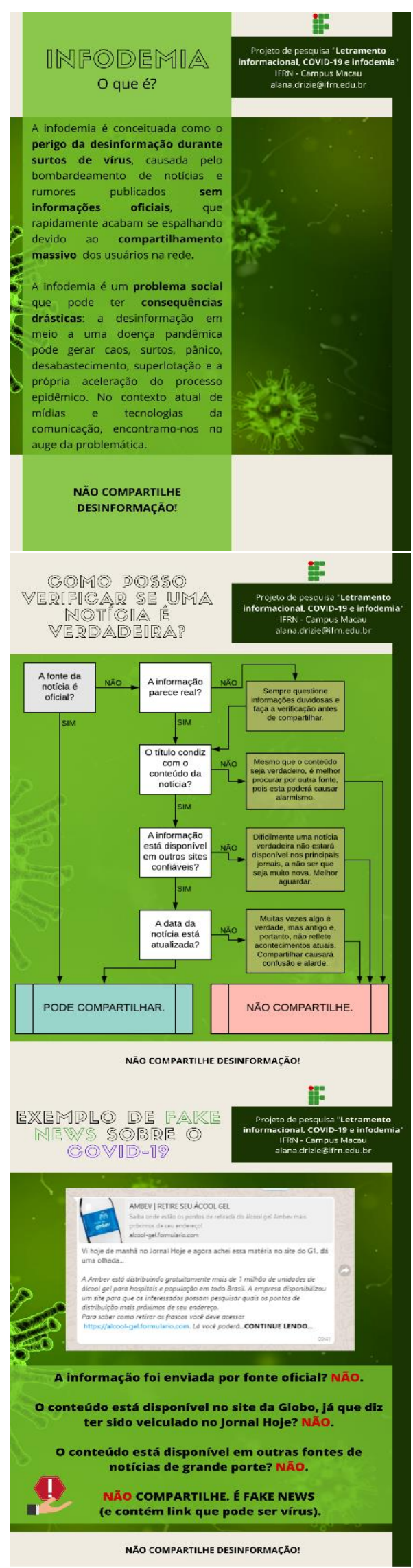

Fonte: Elaborado pelos autores (2020). 
Entre as indicações dispostas na Figura 13, dá-se destaque a incluir, entre as habilidades necessárias a nosso letramento informacional em tempos de pandemia e bombardeamento de dados online, a importância de atentarmos para a configuração dos textos acessados, observando se apresentam informações atuais, com fontes que tenham credibilidade na área, sem distorcer notícias ou fatos. Além disso, possíveis motivações do autor da mensagem devem ser investigadas, assim como a exatidão da informação veiculada.

Diante desse cenário de propagação de fake news, e preocupados com a crescente influência delas nas vidas das pessoas, alguns veículos de informação com grande alcance nacional desenvolveram estratégias de verificação de notícias compartilhadas na rede. No site do Jornal Estadão, é possível consultar a aba "Estadão verifica checagem de fatos e desmonte de boato ${ }^{18 "}$ que objetiva desmistificar boatos sobre a COVID-19 que circulam nas redes sociais e Whatsapp. Na mesma direção, no site do G1, é possível acessar a aba \#Fato ou \#Fake ${ }^{19}$, que apresenta um serviço de checagem de fatos do Grupo Globo.

Assim, é visível a necessidade de que todos os cidadãos se comprometam com a divulgação de informações verídicas, bem como se munam de dados minimamente científicos para respaldar opiniões dadas nas redes a respeito de decisões tomadas a nível de lideranças. Em momentos como o de agora, é urgente que a liberdade de expressão seja utilizada com os devidos compromisso e responsabilidade sociais.

\section{CONSIDERAÇÕES FINAIS}

Considerando as análises empreendidas, entende-se que o Brasil sofre de uma infodemia da COVID-19, encabeçada, principalmente, pelas redes sociais como meios de circulação. Twitter e Facebook lideram entre as plataformas disponíveis para disseminação de (des)informação, o que pode ser justificado tanto pela facilidade no compartilhamento das publicações, com poucos cliques, quanto pela configuração de textos disponível nesses espaços, com a possibilidade da veiculação de links às postagens e com foco na escrita, diferentemente de outras redes sociais nas quais a imagem possui destaque.

Um dos dados observados nesses contextos deve ser alvo de discussão: a quantidade de (des)informação veiculada em contas oficiais de sujeitos que estão à frente de cargos na política brasileira, inclusive, o presidente da república. O propósito de uso das redes sociais como ferramentas de comunicação com a população por esses sujeitos também merece destaque. Desde a eleição de Donald Trump como presidente dos Estados Unidos, em 2016, o Twitter se transformou no principal canal de comunicação de diversos líderes políticos, sendo utilizado, inclusive, para demitir/designar ministros ou dar anúncios oficiais da Administração. Assim, é perigoso observar que, entre publicações de interesse geral da população, acompanhadas por milhares de pessoas, estejam presentes fake news, que facilmente viralizam devido ao alcance dessas contas, podendo gerar consequências de ampla magnitude.

Entre os conteúdos encontrados nessa infodemia, há destaque a três frentes, devido à maior ocorrência no contexto brasileiro: informações sobre o vírus (conspirações

\footnotetext{
${ }^{18}$ Disponível em: <https://politica.estadao.com.br/blogs/estadao-verifica/veja-todas-as-checagens-sobre-coronaviruspublicadas-pelo-estadao-verifical> Acesso em 25 Abr 2020.

${ }^{19}$ Disponível em: <https://g1.globo.com/fato-ou-fake/coronavirus/> Acesso em 25 Abr 2020.
} 
acerca de sua criação, comparação equivocada com outras pandemias), medicamentos contra o vírus (divulgação e uso da cloroquina e de medicamento "secreto", sem os devidos testes clínicos) e quarentena como medida de enfrentamento (declarações que desacreditam orientações internacionais e incitam a população a contrariar a medida).

Nesses textos, observa-se como principal problema a falta de fontes confiáveis para as informações veiculadas, partindo de opiniões, experiências pessoais ou até invenções como estratégias de convencimento para o expectador. Informações desatualizadas ou aumentadas também apareceram nos dados analisados.

Como proposta de intervenção à problemática, foram elaboradas notas informativas, em que apresentamos estratégias para evitar a desinformação acerca da pandemia, por exemplo, questionar se as informações parecem reais, estão disponíveis em outros veículos confiáveis, possuem data atualizada e título condizente com o conteúdo.

Espera-se, com os resultados dispostos, contribuir para as discussões da área no que tange à busca e ao uso de informações, interpretação e a avaliação de sua veracidade e relevância frente à pandemia da COVID-19 no Brasil.

\section{REFERÊNCIAS}

ASSOCIATION OF COLLEGE AND RESEARCH LIBRARY (EUA). Information literacy competency for higher education. Chicago: ALA, 2000. Disponível em: https://alair.ala.org/bitstream/handle/11213/7668/ACRL\%2olnformation\%20Literacy\%20 Competency\%20Standards\%20for\%20Higher\%20Education.pdf?sequence=1\&isAllowed =y. Acesso em: 10 fev. 2020.

ASSOCIATION OF COLLEGE AND RESEARCH LIBRARY (EUA). Framework for information literacy for higher education. Chicago: ALA, 2015. Disponível em: http://www.ala.org/acrl/standards/ilframework. Acesso em: 13 maio 2020.

BESSI, A.; COLETTO, M.; DAVIDESCU, G. A.; SCALA, A.; CALDARELLI, G.;

QUATTROCIOCCHI, W. Science vs conspiracy: collective narratives in the age of misinformation. PloS one, v. 10, n. 2, p. e0118093, 2015. Disponível em:

https://journals.plos.org/plosone/article?id=10.1371/journal.pone.0118093. Acesso em: 10 fev. 2020.

CINELLI, M.; QUATTROCIOCCHI, W.; GALEAZZI, A.; VALENSISE, C. M.; BRUGNOLI, E. L; SCHMIDT, A. L.; ZOLA, P.; SCALA, A. The COVID-19 Social Media Infodemic. ArXive, p. 118, 2020. Disponível em: https://arxiv.org/pdf/2003.05004.pdf. Acesso em: 15 mar. 2020.

GASQUE, K. C. G. D.; TESCAROLO, R. Desafios para implementar o letramento informacional na educação básica. Educação em Revista, Belo Horizonte, v. 26, n. 1, abr. 2010. Disponível em: https://www.scielo.br/pdf/edur/v26n1/03.pdf. Acesso em: 10 fev. 2020.

KIM, L.; FAST, S. M.; MARKUSON, N. Incorporating media data into a model of infectious disease transmission. PloS one, v. 14, n. 2, 2019. Disponível em:

https://www.ncbi.nlm.nih.gov/pmc/articles/PMC6361417/. Acesso em: 10 fev. 2020. 
MACHIN-MASTROMATTEO, J. D. Learning with social media: an information literacy driven and technologically mediated experience. In: KURBANOĞLU, S. et al. Information literacy: Moving toward sustainability: communications in computer and information science, 2015. Disponível em:

http://eprints.rclis.org/31058/1/Learning\%20with\%20social\%20media\%20OA.pdf. Acesso em: 10 fev. 2020.

VICARIO, M. D.; BESSI, A.; ZOLLO, F.; PETRONI, F.; SCALA, A.; CALDARELLI, G.; STANLEY, H. E.; QUATTROCIOCCHI, W. The spreading of misinformation online. Proceedings of the National Academy of Sciences, v. 113, n. 3, p. 554-559, 2016.

Disponível em: https://www.pnas.org/content/pnas/113/3/554.full.pdf. Acesso em: 10 fev. 2020.

VICARIO, M. D.; QUATTROCIOCCHI, W.; SCALA, A.; ZOLO, F. Polarization and fake news: early warning of potential misinformation targets. ACM Transactions on the Web (TWEB), v. 13, n. 2, p. 1-22, 2019. Disponível em: https://arxiv.org/abs/1802.01400. Acesso em: 10 fev. 2020.

WALKER, P. G.; WHITTAKER, C.; WATSON, O. et al. The global impact of COVID-19 and strategies for mitigation and suppression. London: Imperial College London, 2020. Disponível em: https://dsprdpub.cc.ic.ac.uk:8443/bitstream/10044/1/77735/11/2020-0326-COVID19-Report-12-Spanish.pdf. Acesso em 26 Mar 2020.

WARDLE, C.; DERAKHSHAN, H. Information disorder: toward an interdisciplinary framework for research and policy making. Council of Europe, out. 2017. Disponível em: https://rm.coe.int/information-disorder-toward-an-interdisciplinary-frameworkfor-researc/168076277c. Acesso em: 30 abr. 2020.

ZAROCOSTAS, J. How to fight an infodemic. The Lancet, v. 395, p. 676, 2020. Disponível em: https://www.ncbi.nlm.nih.gov/pmc/articles/PMC7133615/pdf/main.pdf. Acesso em: 15 mar. 2020. 